\title{
Formulation of a strategic knowledge management maturity model
}

\author{
C.J. Kruger \\ Department of Informatics \\ University of Pretoria \\ Pretoria \\ Neels.kruger@postino.up.ac.za

\section{M.M.M. Snyman} \\ Department of Information Science \\ University of Pretoria \\ Pretoria \\ msnyman@postino.up.ac.za
}

\section{Contents}

1. Introduction

2. Methodology

3. Institutionalizing knowledge management

4. Knowledge management maturity methodologies

5. ICT maturity in relation to knowledge management maturity

6. Formulation of a strategic knowledge management maturity model

7. Summary

8. References

Key words: Capability maturity model, knowledge management, knowledge management maturity, knowledge strategy, knowledge management strategy

\section{Introduction}

Gallagher and Hazlett (2004:12) are of the opinion that maturity models should be incremental in nature, representing an attempt to interpret a succession of positions, phases or stages with regard to growth and maturity, all with the ultimate aim of improving processes and business performance. These authors therefore criticize current maturity models, arguing that they either 'expend too much effort in trying to address technological concerns', or are 'too vague and offer little in the way of practical assistance' or not enough 'emphasis is placed upon culture and other management issues'. This means that for knowledge to be adequately managed with regard to maturity, organizations must progress to 
the point where they are able to manage knowledge as a strategic resource and also to use this resource in a constructive way, thus enhancing the development of organizational competencies and capabilities. $\mathrm{T}$ his article is aimed at proposing an evolutionary methodology with regard to the progression of knowledge management in an organizational setting. Emphasis is placed on determining maturity from a strategic point of view, rather than from a technological perspective.

In attempting to achieve this aim, the following aspects are given prominence:

- The institutionalization of knowledge management from a strategic perspective

- Knowledge management maturity methodologies

- Information and communications technology (ICT) maturity in relation to knowledge management maturity.

This article is devoted to the formulation of a strategic knowledge management maturity model, one built on the progression and institutionalization of strategic business issues, which are believed to be of vital importance in the quest for the successful institutionalization of knowledge management.

\section{Methodology}

To formulate a knowledge management maturity model capable not only of addressing the objectives and issues of importance regarding knowledge management, but also of addressing limitations present in today's models (particularly from a strategic point of view ), a qualitative research approach was followed. Relevant literature was studied and analysed to identify issues, policies and strategies that are often neglected in maturity models, but need to be addressed if knowledge is to be effectively and efficiently managed as a strategic resource. By placing identified knowledge management issues in chronological order, it was possible to develop an evolutionary methodology with regard to the progression of knowledge management in an organizational setting.

The selection of sources was driven by the need to assess knowledge and knowledge management's role in the process of speeding up the business evolutionary process. Not only was literature analysed in a constantly comparative manner, but a process of analogical reasoning was also followed, for example in constructing a model of a phenomenon on the basis of its similarities to other phenomena.

The line of reasoning followed throughout the article is that although no single approach can cover all the essential aspects involved, knowledge management maturity in relation to strategy formulation can be determined to a certain extent. However, it is argued that this can only be achieved if maturity is a derivative of the ability to institutionalize knowledge issues that have proved to be of such importance and of such a holistic nature that they can be considered to be critical with regard to establishing knowledge management and a knowledge culture within the organization.

\section{Institutionalizing knowledge management}

Chait (1999) proposes that knowledge management requires the concurrent management of four domains, namely culture, content, process and infrastructure. Gallager and Hazlett (2004) argue that in order to manage knowledge in an effective and efficient manner, 
attention needs to be paid to issues such as people, culture, organizational structure and information technology. In a similar fashion, Kazimi, Dasgupta and Natarajan (2004:03) propose that: 'every organisation that needs to leverage its intellectual assets is dealing with knowledge as an asset; communities and cultures as the focal areas; and processes as the medium of institutionalising knowledge management'. Adding to this line of reasoning, Kochikar (2004) is of the opinion that although there is widespread recognition of the need to leverage the power of knowledge, implementation is greatly impeded by the realization that such a path involves significant change, especially with regard to people, process and technology. However, Kochikar (2004) emphasizes that change cannot be achieved in one great leap, and proposes that a staggered approach to the institutionalization of knowledge management be followed. Davenport (1998), Mitre (cited in Taylor, Small and Tattalias 2000), Gartner (cited in Logan 2001), and Snyman and Kruger (2004) argue similarly that the institutionalization of knowledge management is an evolutionary process consisting of different phases and activities taking place over time. In agreement with this, Gallager and Hazlett (2004:04) maintain that 'there is much agreement in literature that managing knowledge effectively requires a time-consuming multidimensional perspective'. To launch this evolutionary process, all the above-mentioned authors are in agreement that endeavours in knowledge management should commence with identifying, determining and deciding on knowledge issues that need to be addressed systematically (institutionalized) in order to render possible or influence knowledge creation activities in an organizational setting.

Puccinelli (1998:40) argues that only high-ranking business managers can 'create an environment that encourages and supports (knowledge) sharing, and knock down the cultural barriers that exist today'. Gallager and Hazlett (2004:08) emphasize that knowledge management cannot be left to grow and develop on its own. In agreement with these statements, Snyman and Kruger (2004) argue that, in the quest to encapsulate and institutionalize knowledge issues, the head (or team) of the knowledge management function should formulate a vision and policy not only to govern the effective use of knowledge, but also to assist in the successful institutionalization of such issues. In a similar manner, Gallager and Hazlett (2004:08) argue that 'Knowledge sharing begins with vision and direction from upper management'.

Zack (1999), Henczel (2000) and Snyman and Kruger (2004) argue that, after issues are decided upon and after policy is put in place to govern the effective use of knowledge, emphasis should be placed on determining where knowledge sources are situated. This means that organizations must know what their knowledge resources are, why certain knowledge can be considered as being strategic and what opportunities are presented by these resources. In agreement with this statement, Gallagher and Hazlett (2004:07) propose that 'any organization attempting to implement knowledge management must first understand its current structure and processes, and also what knowledge is required to make those processes work'. Gallagher and Hazlett (2004:07) argue that 'such a process-orientated view' is synonymous with ideas proposed by Coen (cited in Scheraga 1998), De Long and Miller (1997) and Carnelley (cited in Romberg 1998) with regard to conducting a knowledge audit to establish where gaps in knowledge process provision exist.

Zack (1999), Earl (2001) and Snyman and Kruger (2004) are in agreement that as soon as an organization's knowledge and existing knowledge management profiles are known, these profiles should be brought into context with strategic questions regarding organizational strong points, weak points, opportunities and threats. Zack (1999) argues that as a starting point to bridge the 'gap' between current knowledge and knowledge needed (to base strategy formulization on), a knowledge strategy should be formulated. Arguably this 'first-order' knowledge strategy is primarily aimed at specifically answering strategic questions, and as such relies heavily on competitive intelligence and internal knowledge retrieval systems. As soon as enough knowledge is available to enable strategists to draw a well-informed 
synthesis between organizational strong points, weak points, opportunities and threats, any further knowledge management endeavour should become part and parcel of the normal business strategy formulation process. As such it should be governed by the future direction and goals of the organization. Von Krogh, Nonaka and Aben (2001) maintain that this constitutes the formulation of knowledge management strategies to:

- leverage knowledge throughout the organization (within and between knowledge domains);

- cultivate knowledge from existing expertise;

- extract knowledge from partners and other organizations; and

- develop new expertise by probing new technology or markets.

Nicolas (2004) argues that the characteristics of these strategies will be of a technical, personal or social nature. Authors such as Zack (1999), Von Krogh et al. (2001), Laudon and Laudon (2004) and Snyman and Kruger (2004) assert that central to all of these strategies are knowledge management processes of exploration, creation, acquisition, capture, codification, organization, transferral, sharing, use and distribution, that is, strategies to institutionalize knowledge management issues that have previously been decided upon.

\section{Knowledge management maturity methodologies}

Klimko (2001) argues that maturity modelling is an evolutionary process describing the development of an entity over time, progressing through different levels towards some form of idealistic state. Referring to the capability maturity model (SEI-CMM) developed in the 1990s for the software industry, Mark, Curtis, Chrissis and Webber (1993) define maturity as a specific process of explicitly defining, managing, measuring and controlling the evolutionary growth of an entity. According to Mark et al. (1993), maturity not only implies a potential for growth in capability, but also focuses on richness and consistency with regard to execution. Arguably, to remain true to the notion that survival equals growth and profitability (Pearce and Robinson 2000), any managerial entity progressing through stages of maturity needs to become part and parcel of the organizational decision-making process at some point. Gallagher and Hazlett (2004:12) therefore criticize current knowledge management maturity models, maintaining that they either expend 'too much effort in trying to address technological concerns', or are 'too vague and offer little in the way of practical assistance' or that not enough 'emphasis is placed upon culture and other management issues'. As an example, Gallagher and Hazlett (2004) state that in their view the maturity levels of the Siemens (2004) knowledge management maturity model (KMMM) are of an extremely technical nature, possibly because the model was derived from methodology applicable to the software industry's SEI-CMM model.

In an attempt to integrate and further develop current theory, Gallagher and Hazlett (2004:11) propose a knowledge management maturity model (KM3) consisting of four stages: aware, managed, enabled and optimized. They are of the opinion that 'in contrast to other maturity models, relating specifically to information system usage' their model also considers other dimensions, especially the human dimension, and its interconnectedness with technology and infrastructure. Like Gallagher and Hazlett (2004), Kochikar (2004) proposes a knowledge management maturity model (KMM model) characterized by certain observable capabilities among each of the major components of people, process and technology. However, because these maturity models are also derived from the Software Engineering Institute's capability maturity model, both the KM3 and the KMM closely resemble the Siemens 2004 KMMM model, especially with regard to the progression of stages. It should be noted, however, that even though there are many similarities between these models, 
especially with regard to the progression of stages, there is also major disagreement about what specifically constitutes areas of importance within these stages. For example, the capability maturity model postulates that there are 18 key process areas, the KMM model that there are 15 key result areas, and the KMMM that there are only eight areas of importance. In essence, the model proposed by Gallagher and Hazlett (2004) simplifies key areas and postulates that only three components are of extreme significance. Interestingly, because these knowledge management maturity models are based on the Software Engineering Institute's capability maturity model, they all closely resemble the maturity regression of initial, aware, managed and optimized as proposed by Hirvonen (2004), with regard to ICT maturity.

Authors such as Botha and Fouche (2002) and Kazimi et al. (2004) question whether knowledge management maturity should be based on the Software Engineering Institute's Capability Maturity Model at all. These authors argue that because we are working with abstract components (knowledge, culture, processes or communities) there is a great deal of disillusionment about knowledge management that first needs to be addressed. As in the proposition put forward by Gallagher and Hazlett (2004), Kazimi et al. (2004) also propose that knowledge management maturity models should focus not only on technological issues, but also on dispelling disillusionment with regard to knowledge management, thus making organizations aware of the following:

- What they want to transform into - maturity framework

- How to create visibility from an invisible asset like knowledge - maturity plateaux

- What efforts need to be carried out and in which directions - maturity dimensions

- How to keep focused on business strategy and profit from these efforts - maturity drivers.

Kazimi et al. (2004) are therefore of the opinion that current knowledge management maturity models derived from the SEI-CMM, and/or based on predefined business dimensions to chart out maturity, unfortunately only address a few of the above-mentioned issues and therefore cannot fully address the subject of knowledge maturity. In emphasizing this point, Kazimi et al. (2004:04) argue that these models are based on a 'project environment' and as such focus on 'a set of symptoms indicating the adoption of stable, standardized processes', e.g. processes to create, capture, store, retrieve and disseminate knowledge within the organization. Kazimi et al. (2004:04) argue that even though some of the models derived from SEI-CMM [arguably also the model Gallagher and Hazlett (2004) propose] have led to the identification of pillars (knowledge issues) that support knowledge management (people, process, technology and strategy), and even though these models have enabled organizations to understand that knowledge management is not just another technology solution, there are also other issues (leadership, culture and communities) that need to be addressed. Using a modified version of the Likert scoring scale, Botha and Fouche (2002:14) basically came to the same conclusion and they maintain that a high degree of proficiency in knowledge management is determined by the successful execution of six business processes, namely knowledge leadership, organizational culture and values, business processes, organizational structures, technological infrastructure and the 'existence of procedures to measure on an ongoing basis the organization's proficiency in sustaining and improving the other five characteristics'.

Kazimi et al. (2004:04) are of the opinion that owing to limitations with regard to addressing all of the above-mentioned knowledge issues, and/or owing to the fact that not all organizations are categorized according to projects, models based on the SEI-CMM are not of a sufficiently generic nature, and they therefore question the extent to which progress across these models really relates to knowledge management maturity. Kazimi et al. (2004:05) consequently question whether organizations represented with a full circle of 
maximum radius (maximum growth along each dimension) are indeed the most mature knowledge organizations. They feel that 'graphical representation [of these issues] is [no more than] an effective tool for conducting a knowledge audit', that is understanding an organization's readiness for knowledge management and identifying thrust areas (knowledge issues). It would seem that the arguments proposed by Kazimi et al. (2004) are similar to the proposition put forward earlier that as a point of departure, organizations should first identify knowledge issues, formulate policy to guide the institutionalization of these issues, conduct an audit to determine where knowledge resources are situated and, in the quest to address and institutionalize issues, relate the management of knowledge (as a strategic resource) to the principles involved in strategy formulation. In other words, organizations should not only formulate strategy to utilize knowledge as a strategic resource, but also use the strategy formulation process to guide the institutionalization of knowledge management strategies, planning and processes. Emphasizing that the methodology they propose is similar to the above-mentioned line of reasoning, Kazimi et al. (2004:05) maintain that 'what determines an organization's knowledge maturity is how well it can execute its business strategy by capitalizing on its knowledge strengths and opportunities, and by mitigating the risks of its knowledge weaknesses and threats' or, stated differently, 'the ability of an organization to create knowledge and provide long-term business advantage will determine its maturity' (Kazimi et al. 2004:06). They therefore propose that a new model of knowledge management maturity needs to be formulated, a model capable not only of addressing the objectives and issues of importance with regard to knowledge management, but also of addressing limitations present in current models. Kazimi et al. (2004:06) are of the opinion that this 'may well be the beginning of a new step-by-step Knowledge Management methodology which will blow away many of the clouds that come in the way of implementing and enabling organizations to move towards Knowledge Maturity'.

\section{ICT maturity in relation to knowledge management maturity}

It would seem that because most ICT and knowledge management maturity models are derived from the Software Engineering Institute's capability maturity model, and also because so many authors agree that knowledge management is dependent on ICT, it should be possible to derive a more holistic ICT knowledge management maturity model simply by superimposing some of these models upon one another. This, however, would mean that knowledge management would have to be an extension or an essential part of ICT management, or vice versa, precisely the trap that authors such as Kazimi et al. (2004) and Gallagher and Hazlett (2004) warn us not to fall into. However, the authors believe that in determining the best way to institutionalize knowledge management this avenue should be explored, with the proviso that other knowledge management issues needing to be addressed should also be taken into account.

At first glance, such a proposition might seem far-fetched, but considering that the progression of knowledge (as a strategic resource) follows the methodology of the transition of data into information and then into knowledge, this proposition might not be so preposterous at all. It can be argued that the management of data, information and knowledge should follow the same line of reasoning.

To emphasize this close correlation between knowledge and ICT management - as in the models proposed by Gallagher and Hazlett (2004), and Kochikar (2004) - Ross, Breath and Goodhue (1996) assert that three ICT assets need to be managed well in order for ICT to play a strategic role: a technology asset, a human asset and a relationship asset. These are all areas deemed to be of extreme importance to successful knowledge management. 
Of interest is the fact that the evolution of ICT systems does indeed seem to follow this methodology. Applegate, McFarlen and McKenny (1999), building on the work of Zwass (1998), argue that the role information systems play in organizations evolves over time. According to these authors, the stages in which an organization finds itself with regard to ICT management can be divided into four eras:

- Operational support: This primarily involves shifting data in support of business operations.

- Support for management and knowledge work: With the aid of personal computers, information systems go beyond the support of operations to support management and knowledge work as well.

- Support of business transformation and competition: Organizations rely on information systems to achieve and sustain competitive advantage. Decision support and strategic information systems directly support knowledgeable decision-making and group decision-making and even render them possible.

- Ubiquitous computing: ICT systems extend the influence of the organization beyond its borders. Systems tend to share knowledge and expertise with all stakeholders in an extended value chain.

In scrutinizing this evolutionary process, it becomes evident that the ICT systems being developed to suit the needs of later stages are all directed towards the enabling power of knowledge, emphasizing an increased interdependency between ICT management and knowledge management, especially with regard to increased maturity. In agreement with this, Kazimi et al. (2004:1) state that 'today there is a growing realization that organizations can attain maturity in knowledge management only through a healthy coexistence of technology, processes and people, thereby paving the way for knowledge management successes in the years to come'. This phenomenon highlights the fact that in the past, knowledge management and ICT management have mistakenly been managed as separate managerial entities.

A note of caution must be sounded here. One must not fall into the trap of trying to replace 'information' or 'data' with the word 'knowledge', presuming that ICT systems tending to support these entities can in all circumstances support, or be adapted to support, knowledge management. What is, in fact, being proposed is similar to a proposition by Kazimi et al. (2004) who argue that, due to subtle differences between data, information and knowledge, the tools for managing these entities will in most cases not be the same, although the underlying technology will remain the same. In the organization's quest to continue growing and be profitable, there is an evolutionary process of converting data into information and then into knowledge, with knowledge being the ultimate strategic resource. In all of these endeavours, ICT is the vehicle or rather the technology that can supply the tools to manage data, information and knowledge efficiently and effectively.

As argued earlier, by looking at the evolution of both ICT management and knowledge management, it is easy to understand why discrepancies arose. During the infancy of both managerial entities, it was not obvious that there is a correlation between shifting data and sharing knowledge. However, when organizations reach the later stages of both ICT and knowledge management, the rationale behind both ICT management and knowledge management changes into a quest to supply sufficient information to decision makers to enable them to formulate winning strategies. Ironically, Applegate et al. (1999), (referring to ICT management) predicted that as soon as ICT becomes mature within an organization, ICT systems evolution becomes prone to (first) supporting sharing data, then information and finally knowledge beyond the borders of the organization. In a similar fashion, Gallagher and Hazlett (2004) propose that after optimization of knowledge management within the organization, the next step would be following a path leading to knowledge management 
integration - a path towards sharing knowledge beyond the borders of the organization. Of interest is the fact that Kochikar (2004) came to basically the same conclusion, stating that the knowledge life cycle not only consists of the stages of knowledge acquisition, sharing/dissemination and reuse, but also that there is a fourth dimension - a dimension that only comes into play in the later phases of knowledge management maturity. According to Kochikar (2004), this fourth (next) dimension in the knowledge life cycle is virtual teamwork, that is, the ability to support knowledge transfer across geographical distances, even beyond the organization's boundaries.

It is postulated that all of the above-mentioned criticisms with regard to determining knowledge management maturity boil down firstly to maturity models neglecting to successfully identify all issues of importance with regard to knowledge management and, secondly, failing to relate the institutionalization of these issues to the organizational quest for growth and profitability. It is becoming clearer and clearer that knowledge management maturity should be more than just a derivative of the ability to identify and institutionalize certain issues (the establishment of knowledge and knowledge management capabilities and competencies within the organization). Knowledge management maturity should also encompass the ability to identify and relate knowledge management issues to organizational growth and profitability. This argument is in agreement with a proposition put forward by Kazimi et al. (2004), emphasizing that, in order to manage knowledge successfully, organizations first need to establish knowledge as a strategic asset and then utilize such knowledge to provide strategic leverage in terms of competitive advantage, increased market share and increased intellectual capital. It would seem that for knowledge to be properly managed, organizations must progress to a point where they are able to manage both ICT and knowledge simultaneously. Therefore, it is proposed that by building checks and balances into the evolutionary path of both ICT and knowledge management, a holistic knowledge management maturity model can be formulated. The next section is a brief explanation of the proposed model (Figure 1).

\section{Formulation of a strategic knowledge management maturity model}

Figure 1 Knowledge management maturity model 


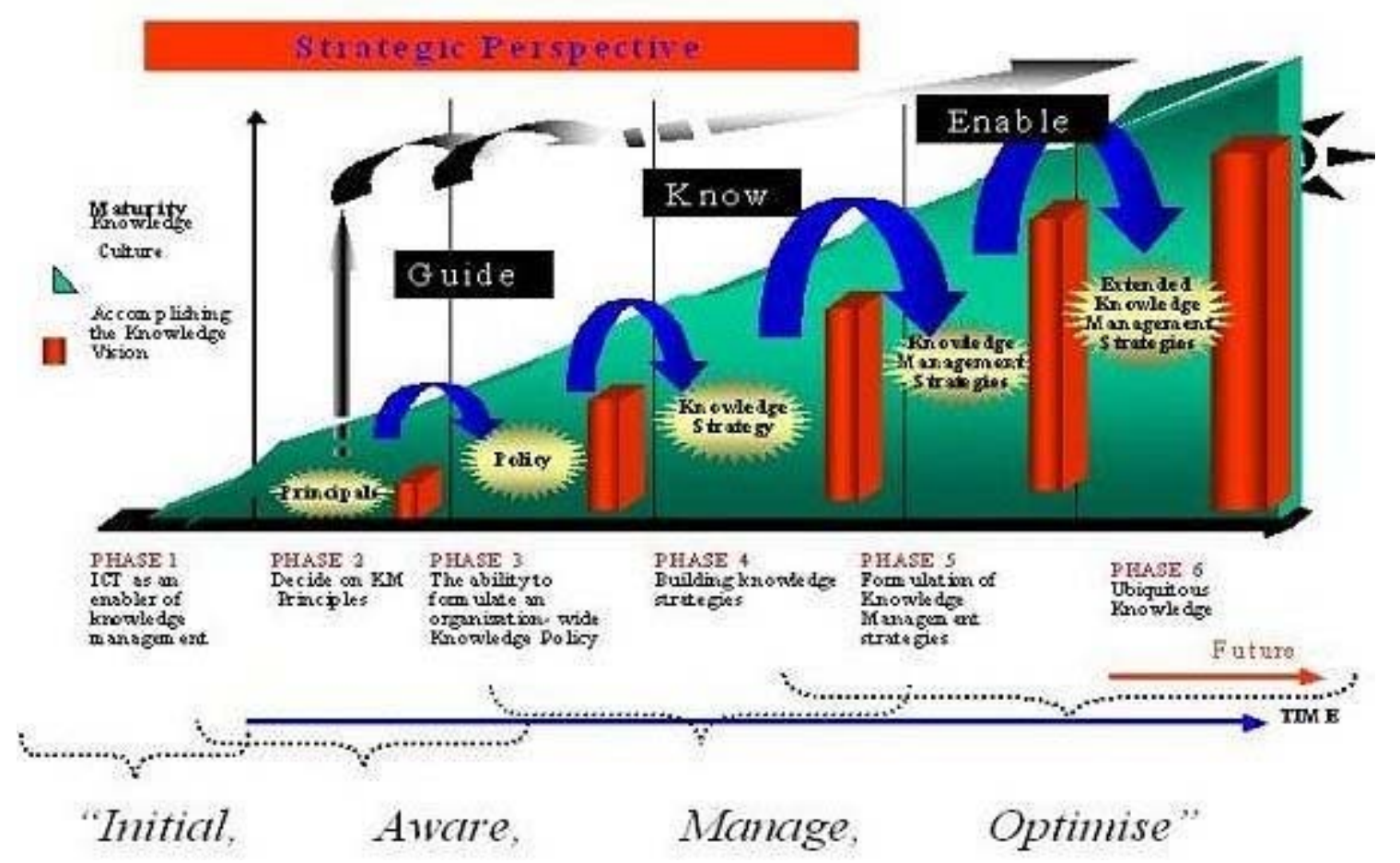

Phase 1: ICT as an enabler of knowledge management

The following factors are characteristic of this phase:

- Organizations are not yet aware of the power vested in knowledge and/or the importance of knowledge as a strategic resource.

- ICT (if it is present within the organization) is not managed in an effective and efficient manner. Organizations are still getting to grips with the way they handle data and information. There is a need to develop an understanding of existing ICT systems, ICT technology, where information resources are situated and what the capabilities of technical personnel are, etc.

Primarily, all knowledge still resides in the head of the 'knower', and if it is being shared, this is done in an informal manner.

\section{Phase 2: Deciding on knowledge management principles}

During this stage, ICT systems within the organization evolve to a level where the organization knows what constitutes data and information systems. There is a realization of the importance of knowledge, recognition of a formal knowledge management function, and an associated drive to instil this realization into all levels of the organization.

Endeavours in knowledge management start off with the identification of issues, success factors and elements that lend themselves to the inculcation of a culture of knowledge and knowledge management architecture within the organization. To focus efforts, there is a distinct expression of the future state of knowledge (the formulation of a knowledge vision) within the organization.

Phase 3: The ability to formulate an organization-wide knowledge policy

The primary goal of this phase is the formulation of an organization-wide knowledge policy - high-ranking policy on how the organization is going to manage, secure and protect knowledge as a strategic resource (both tacit and explicit); as well as guidelines on how the 
organization's knowledge repository should be formulated. At this level of maturity, ICT systems evolve to a stage where they are capable of going beyond merely supporting operations to the point of being capable of supporting management decisions and knowledge work.

This level constitutes a realization among business managers that knowledge is of extreme importance. During the last part of this phase there is a realization that for knowledge to have an exponential effect, it must be shared throughout the organization. Thus, the main thrust of this phase is a conscious decision to establish a knowledge management function, knowledge domains, as well as forums, to provide knowledge management with governance guidelines.

\section{Phase 4: Building knowledge strategy/strategies}

At this level, efficient and effective ICT architectures and knowledge infrastructures are in place. During this phase managers become more than just aware of the power vested in knowledge. They consciously start encouraging endeavours in knowledge management.

Organizations at this level of maturity are able to determine what constitutes knowledge resources (both tacit and explicit), where knowledge resources are situated (internal and external), and why resources are strategic. At this stage strategists are starting to become empowered to formulate business strategies, based on knowledgeable reasoning.

\section{Phase 5: Formulation of knowledge management strategies}

At this level, strategists begin to perceive ICT and knowledge management as interdependent entities, irreplaceable in the drive to sustain competitive advantage. Where knowledge is insufficient to supply answers to strategic questions, and/or where strategists point out that 'new and more' knowledge and intellectual capital are needed, the power of existing internal knowledge resources is leveraged. Organizations are capable of formulating efficient and effective plans to change the organization's knowledge structure and of supporting ICT structure from the 'as is' to the required 'should be' structure.

Central to plans and strategies is the objective of institutionalizing knowledge and ICT systems that gradually enhance the effectiveness and efficiency of the organization's ability to explore, create, acquire, transfer, capture, codify, share and distribute knowledge. 'More of what [knowledge] goes out, comes in' (Kochikar 2004:09).

\section{Phase 6: Ubiquitous knowledge}

During this phase, knowledge management seamlessly integrates with the enterprise ecosystem consisting of customers, business partners, (shareholders, alliances, etc.), operations and vendors (Kazimi et al. 2004:06). The organization's ICT architecture must now be capable of transcending the borders of the organization, for example capable not only of sharing data and information, but also knowledge and expertise with all stakeholders in the organization's extended value chain. The focus is not only on determining whether or not knowledge is being shared among value chain partners, but more specifically to what extent knowledge management is institutionalized between partners. In essence, this means that organizations return to Phase 1 of the maturity model, and once again progress through all these phases, this time adding the sharing of knowledge across boundaries to the line of reasoning, for example deciding on knowledge issues applicable to all stakeholders, formulating a knowledge policy to govern the sharing of knowledge across the extended value chain, formulating holistic knowledge strategies, etc. 
The evolution of knowledge management beyond the point of sharing knowledge between partners in an extended value chain remains a mystery. It is believed that in the future, if knowledge is going to be regarded as the organization's most precious resource, this will necessitate the sharing and trading of knowledge even beyond the boundaries of the organization's extended value chain. A point could be reached where endeavours in knowledge management reach saturation point, a point at which the cost of sustaining an extended knowledge management infrastructure could no longer be financially justified, and/or technologically supported. This could give rise to a situation in which knowledge management, in the terminology of the 'big bang theory', splits up, implodes and collapses back into the organization.

It should be noted that the transition from one phase to another is not cast in concrete discrepancies and divergence between phases are a reality. The model should therefore not be seen as being too prescriptive. As mentioned by Gallagher and Hazlett (2004:14), it is not a hard-and-fast rule that in all cases organizations should zealously strive to progress to the next evolutionary level. Under certain circumstances, before attempting a successive phase, it might be necessary to embark on a period of discontinuity, spending time reflecting on what has been achieved. Even though progressions through phases should bring the organization closer and closer to reaching its ultimate knowledge vision, organizations constantly need to revisit and amend prior phases. For example, knowledge issues, success factors, policy and strategy need to be constantly revised in order to cope with changes in the organization's internal and external environment.

\section{Summary}

In this article it is proposed that a new model for knowledge management maturity should be formulated, one that is not only capable of addressing the major objectives and issues of knowledge management, but also one capable of addressing limitations present in today's models (Kazimi et al. 2004). Following this line of reasoning, this article emphasizes that certain issues, policies and strategies need to be addressed within an evolutionary methodology to enable knowledge to play a significant role in the formulation of strategy. Perusal of the literature on the issues that are deemed to be important in respect of knowledge management established that there seems to be consensus regarding the enabling role that ICT plays, especially in the later stages of knowledge management. However, current theory also maintains that this possibly placed limitations on the way knowledge management maturity was established in the past, leading to a lack of acknowledgement of the enabling role that other issues also play in this regard. Therefore, by placing knowledge management issues in a chronological order, an evolutionary methodology with regard to the progression of knowledge management in an organizational setting was formulated - a methodology not built solely on determining capability maturity (i.e. initiate, be a ware, manage and optimize), but rather, a methodology built on determining the progression of strategic business issues related to knowledge management.

\section{References}

Applegate, L.M., McFarlen, W.F. and McKenny, J.L. 1999. Corporate information system management: text and cases. Boston: Irwin/McGraw-Hill. 
Botha, D.F. and Fouche, B. 2002. Knowledge management practice in the South African business sector: preliminary findings of a longitudinal study. South African Journal of Business Management 33(2):13-19.

Chait, L.P. 1999. Creating a successful knowledge management system. The Journal of Business Strategy 20(2):23-26.

Davenport, T.H. 1998. Some principles of knowledge management. [Online]. Available WWW: http://www.bus.utexas.edu/kman/kmprin.htm\#TOC (Accessed 12 August 2004).

De Long, D. and Miller, H. 1997. Caselets from knowledge management interviews. [Online]. Available WWW: http://www.businessinnovation.ey.com (Accessed 12 August 2004).

Earl, M. 2001. Knowledge management strategies: towards a taxonomy. Journal of Management Information Systems 18(1):215-233.

Gallager, S and Hazlett, S. 2004. Using the knowledge management maturity model as an evaluation tool. [Online]. Available WWW: http://s.gallagher@qub.ac.uk (Accessed 12 August 2004).

Henczel, S. 2000. The information audit as a first step towards effective knowledge management: an opportunity for the special librarian. Inspel 34(3/4):210-226.

Hirvonen, A.P. 2004. Application portfolio models in practice: a comparative study with public sector and business organizations. [Online]. Available WWW:

http://ari.p.hirvonen@tietoenator.com/ (Accessed 12 August 2004).

Kazimi, J., Dasgupta, R.R. and Natarajan, G. 2004. The rise, fall and rise of knowledge management. [Online]. Available WWW: http://www.zenzar.com/pdfs/km2.pdf (Accessed 12 August 2004).

Klimko, G. 2001. Knowledge management and maturity models: building common understanding: Proceedings of the 2 nd European Conference on Knowledge Management, IEDC Bled School of Management, Bled, Slovenia, 8 - 9 November 2001. Reading: Academic Conferences Limited: 269-279.

Kochikar, V.P. 2004. The knowledge management maturity model: a staggered framework for leveraging knowledge. [Online]. Available WWW:

http://www.infy.com/knowledge_capital/knowledge/KM (Accessed 12 August 2004).

Laudon, K.C. and Laudon, J. P. 2004. Management information systems. 8 th ed. Upper Saddle River, New Jersey: Pearson Education.

Logan, D. 2001. Knowledge management scenario: measuring and managing intellectual assets, Gartner Symposium /ITxpo Africa, Sandton, South Africa (Unpublished).

Mark, P., Curtis, B., Chrissis, M. and Webber, S. 1993. Capability maturity model, version 1.1. IEEE Software, 10(3): 7-27.

Mouton, J. 2001. How to succeed in your master's and doctoral studies: a South African guide and resource book. Pretoria: Van Schaik.

Nicolas, R. 2004. Knowledge management impacts on decision making process. Journal of 
Knowledge Management 8(1): 20-31.

Pearce, J.A. and Robinson, R.B. 2000. Strategic management, formulation, implementation and control. 7 th ed. Boston: Irwin: McGraw-Hill.

Puccinelli, B. 1998. Strategies for sharing knowledge. Inform (October).

Romberg, D. 1998. Knowledge management market to hit \$5 billion. Computing Canada October 26.

Ross, J.W., Breath, C.M. and Goodhue, D.L. 1996. Develop long-term competitiveness through IT assets. Sloan Management Review 38(1):31-42.

Scheraga, D. 1998. Knowledge management competitive advantages become a key issue. Chemical Market Reporter October 26.

Snyman, M.M.M. and Kruger, C.J. 2004. The interdependency between strategic management and strategic knowledge management. Journal of Knowledge Management, 8 (1):5-19.

Taylor Small, C. and Tattalias, J. 2000. Knowledge management model guides KM process. The Edge Newsletter (April). [Online]. Available WWW:

http://www.mitre.org/pubs/edge/april_00.htm (Accessed 12 August 2004).

Von Krogh, G., Nonaka, I. and Aben, M. 2001. Making the most of your company's knowledge: a strategic framework. Long Range Planning 34(1):421-439.

Zack, M.H. 1999. Developing a knowledge strategy. California Management Review 41 (3):125-145.

\section{Disclaimer}

Articles published in SAJIM are the opinions of the authors and do not necessarily reflect the opinion of the Editor, Board, Publisher, Webmaster or the Rand Afrikaans University. The user hereby waives any claim he/she/they may have or acquire against the publisher, its suppliers, licensees and sub licensees and indemnifies all said persons from any claims, lawsuits, proceedings, costs, special, incidental, consequential or indirect damages, including damages for loss of profits, loss of business or downtime arising out of or relating to the user's use of the Website. 
ISSN 1560-683X

Published by InterWord Communications for Department of Information and Knowledge Management, University of Johannesburg 